Another method of measuring the effect of ward design on the transfer of infection is to study the acquisition of nasal carriage of Staphylococcus aureus. ${ }^{7}$ Here again the results from the new Sydney ward were encouraging, in that carriage of multiple-resistant strains was less frequent in the new ward than in the old, though it was disappointing to find that when a particularly communicable strain of staphylococcus was introduced it was able to spread rather readily. Airborne spread of bacteria might be expected to be reduced by structural subdivision of the ward area, so estimates of the spread of airborne bacteria from one part of the ward to another might provide a further method of assessing ward design. Professor Loewenthal and his colleagues found that there was some diminution in the frequency of air contamination with staphylococci but do not report on the transfer between different parts of the ward.

There are many requirements apart from the prevention of cross-infection that have to be satisfied in a good ward design, and at a time when we are beginning to have some new wards in use and many more on the drawing-board it is important to devise methods for reasonably precise estimation of the relative advantages of different designs for layout, equipment, and organization, and to make sure that these methods are applied in new wards with all speed. The Australian workers have provided a good example of what can be achieved by relatively simple techniques. But possibly more elaborate statistical techniques may be needed, such as those being explored by Lidwell and his colleagues, ${ }^{8}$ to obtain useful results in time to influence the next round of hospital planning.

1 Loewenthal, J., Brit. med. 7., 1962, 1, 1437.

2 May, J., Chalmers, J. P., Loewenthal, J., and Rountree, P. M., Surg. Gynec. Obstet., 1966, 122, 28.

3 Report of the Public Health Laboratory Service, Lancet, 1960, 2, 659.

- Rountree, P. M., Harrington, M., Loewenthal, J., and Gye, R., ibid., $1960,2,1$.

- Lidwell, O. M., f. Hyg. (Lond.), 1961, 59, 259.

- Kippax, P. W., and Thomas, E. T., Lancet, 1966, 2, 1297.

' Williams, R. E. O., Bact. Rev., 1966, 30, 660.

${ }^{3}$ Lidwell, O. M., et al., F. Hyg. (Lond.), 1966, 64, 321.

\section{Rheumatic Fever Prophylaxis}

Penicillin is of indisputable value in preventing streptococcal infections of the throat and thus recurrences of rheumatic fever in people who have had a previous attack. Methods of administering it vary, and there are different views about how long it should be continued. The official recommendation" in Britain is "until leaving school or for five years, whichever is the longer." A recent paper reports an attempt to determine the utility of this procedure after a certain lapse of time by comparing penicillin-treated patients with untreated controls.

The study was carried out by A. R. Feinstein and his colleagues $^{2}$ at the Irvington House Outpatient Rheumatic Fever Research Clinic, New York, on 161 patients aged 14-24 years with an unequivocal history of rheumatic fever but no present evidence of heart disease. It was a condition of admission to the trial that five years should have elapsed since the attack of rheumatic fever in patients aged 14 or 15 and three years in those aged 16 or more. The numbers of younger patients were equal in the treated and control groups, as were those of patients who had evidence of carditis in the original attack. Alternate patients were given tablets containing 200,000 units of potassium penicillin G, one of which was to be taken daily before breakfast, and an indistinguishable placebo. The identity of the two tablets was known only to the supply officer. The trial began in May 1962 and was concluded in September 1964. During this time the patients were seen regularly, the causes of throat infections were identified, and the usual serological tests were done. The results can be stated very shortly: in each of the two groups, 82 on penicillin (138 patient-years) and 79 on placebo (140 patient-years), there were precisely 30 attacks of streptococcal infection (attack rates of 22 and $21 \%$ ), and respectively 1 and 2 recurrences of rheumatic fever, a difference which is rather superfluously described as " not statistically significant."

This investigation is held to "demonstrate the relative safety with which antistreptococcal prophylaxis could be dis- continued in . . rheumatic patients in or beyond the later stages of adolescence, free of heart disease, and remote from a recent rheumatic attack." This reassuring conclusion will be welcomed, but the findings seem to raise another question altogether. In view of the almost identical attack rates of streptococcal infection in the two groups, is this dose of this form of oral penicillin protective? That it may not be is supported by another piece of evidence from this trial. Patients were questioned about the regularity with which the tablets were taken, and were classified accordingly into "good" and "not good" "fidelity of prophylaxis." The attack rates of streptococcal infection in these two categories were 21 and $23 \%$ in the group on penicillin and 20 and $24 \%$ in the group on placebo, which seems to suggest that fidelity of prophylaxis was immaterial.

The authors themselves raise this question, but counter it by contrasting results in two previous studies of daily oral penicillin-in one of which in fact a dose was given twice a day-and in a study in which treatment was given for only ten days in each month, when the results were distinctly inferior. The efficacy of a single daily oral dose of penicillin $\mathrm{G}$ can also be judged from studies in which its effects have beein compared with monthly benzathine penicillin by injection and with sulphadiazine. In the impressive series reported from the same clinic by H. F. Wood and colleagues ${ }^{3}$ the streptococcal-infection rates per 100 patient-years on oral penicillin, benzathine penicillin, and sulphadiazine were $20.7,6.1$, and 24 , and the recurrence rates for rheumatic fever were respectively $5.5,0.4$, and 2.8 .

Clearly penicillin $G$ by mouth was far inferior to benzathine penicillin by injection. This is not in the least surprising. Oral penicillin $G$ is poorly and irregularly absorbed, and a single dose can at best provide some sort of level in the blood

\footnotetext{
1 Prevention of Initial Attacks and Recurrences of Rheumatic Fever, 1960. Ministry of Health, London.

Feinstein, A. R., Spagnuolo, M., Jonas, S., Levitt, M., and Tursky, E., J. Amer. med. Ass., 1966, 197, 949.

- Wood, H. F., Feinstein, A. R., Taranta, A., Epstein, J. A., and Simpson, R., Ann. intern. Med., 1964, 60, Suppl. No. 5, 31

- Eagle, H., f. clin. Invest., 1949, 28, 832.
} 
for four hours out of the 24. It is a treatment which is rarely given except for this purpose and because of this recommendation by the American Heart Association. It seems unfortunate that these extensive studies have not included groups of patients treated with an acid-resistant penicillin, whether penicillin $\mathrm{V}$ or one of those more recently introduced, which, being more regularly absorbed, may be depended on to attain an adequate blood level. It is also doubtful whether a single daily dose should be considered adequate. The time taken by streptococci to recover from exposure to penicillin has been fully investigated, ${ }^{4}$ and to allow them at least 18 hours' freedom out of the 24 is too much.

The British official recommendation ${ }^{1}$ is two daily doses of either 200,000 units of penicillin $G$ or $125 \mathrm{mg}$. penicillin V. If the patients in the Irvington House study had been given penicillin $V$ twice a day instead of penicillin $G$ once would the frequency of streptococcal infection have been the same as in the placebo group? Almost certainly not. It would be interesting to review all these results in the light of an assumption that a single daily oral dose of penicillin $G$ has not in fact the protective effect with which it has been credited.

\section{Future of Clinical Pharmacology}

Recently it was suggested in these columns ${ }^{1}$ that the relationship of pharmacology to clinical medicine needs reviewing and that pharmacologists too often find that work in hospital does not provide a satisfactory career. ${ }^{23}$ Certainly much of the research they carry out contains little of direct interest to a practising doctor. Yet he may be daily prescribing drugs discovered in the last ten years and so need to understand their properties. Pharmacologists are apt to be seen mainly as laboratory scientists, investigating drugs in experimental circumstances remote from the practical problems of therapeutics. How many drugs of therapeutic value have been excluded from testing in man-and probably rightly-because they injured animals of one or another species is of course unknown. Public opinion, when not falling into anti-vivisectionist extremes, is all in favour of thorough testing of drugs in animals, and to this extent pharmacologists are swimming with the political tide. ${ }^{4}$

The need for more clinical pharmacologists is generally acknowledged among practising physicians as much as among clinical pharmacologists themselves, but appointments with this title are rarely created, and indeed there is much dispute about exactly what a clinical pharmacologist ought to do. The problem is complicated by the distinction maintained between consultants with "direct clinical responsibility" and other doctors. So long as the first question asked about a clinical pharmacologist is, Will he have beds ? confusion will follow. If the answer is yes, then clinical pharmacology is restricted to those doctors who have followed the correct sequence of hospital appointments and higher diplomas and not made the error of diverting their career for more than a year or two to obtain some basic training in scientific method in general and experimental pharmacology in particular. If the answer is no, then the appointment is, under present conditions, unlikely to have consultant status and reward. No scientist of sufficient ability to study the complex problems of the actions and uses of drugs in man is keen to accept such a position in preference to a university chair or a senior appointment in industry. The innovation of a diploma course in clinical pharmacology at Manchester University ${ }^{5}$ is a step in the right direction, but it remains to be seen what status will be achieved by virtue of holding the diploma. The first question ought to be : Is expert guidance in the use of drugs in patients necessary ? Evidence from hospital ${ }^{6} 7$ and general practice $^{8}$ and the incidence of illness caused by drugs ${ }^{9} 10$ all suggest that it is.

Many aspects of the use of drugs in hospital need further study. ${ }^{11}$ Research is needed on the absorption and fate of drugs in man as well as on their therapeutic and toxic properties. Clinical trials must be designed, carried out, and analysed. Operational research on the everyday use of drugs is also important, because the detailed care which is part of a good clinical trial is not always practicable, and the success (or failure) of a drug under special test conditions may not be a fair indication of its potential in ordinary service. Information about new drugs ought to be disseminated throughout medical staff generally-particularly knowledge about the interactions of drugs and special contraindications. The time is long past when any of these duties can devolve on the understaffed, overpressed hospital pharmacist. They should be a matter for the clinical pharmacologist.

It is surely helpful too for hospitals to keep full records of the use of recently introduced drugs and of untoward effects of all kinds observed in patients under treatment. Without such recording another tragedy like that of thalidomide remains a haunting possibility, for new hazards may arise which cannot be prevented by any amount of initial testing on animals. If a drug has an observable effect it has a recordable effect, and to direct more clinical observation towards the study of these effects could only make for safer, more effectual, and more economical therapy. Thus the creation of a hospital pharmacological service might be considered, comparable in standing with the clinical pathological service and with a consultant clinical pharmacologist at its head. Professor K. Naess, ${ }^{12}$ of Oslo, has recently emphasized mary of these points in the World Medical fournal, and states: "The object must be to create a clinical pharmacological environment such that the different branches of pharmacology including its practical application do not split up into separate disciplines, a trend now very much in evidence."

At present pharmacologists are leaving the universities and moving to industry. ${ }^{2}$ The drift is not surprising. The facilities and the rewards are attractive, and the discovery of new drugs is more exciting than the appraisal of remedies already in use. If the movement between universities and industry were really two-way it would be commendable, but the attraction of the universities to industrial pharmacologists is evidently insufficient to promote much return flow. Yet the study of drugs in man should be no less thorough than their study in animals, and many doctors in hospitals and in general practice would welcome more guidance on prescribing.

\footnotetext{
Brit. med. F., 1966, 2, 1152.

2 Bakhle, Y S., and Paton, W. D. M., Brit. F. Pharmacol., 1966, 27, 239 Pharmacology as a Career, British Pharmacological Society, Cardiff 1966.

Macgregor, A. G., in Absorption and Distribution of Drugs, p. 252 edited by T. B. Binns. Edinburgh. 1964.

- Brit. med. F. 1966, 2, 1542.

- Crooks, J., Clark, C. G., Caie, H. B., and Mawson, W. B., Lancet, 1965, 1, 373.

- Vere, D. W. ibid., 1965, 1, 370

Lee, J. A. H., Weatherall, M., and Draper, P., Proc. roy. Soc. Med. $1964,57,1041$

- Brit. med. f., 1965, 1, 982.

10 Modell, W., Ann. Rev. Pharmacol., 1965, 5, 285.

12 Laurence, D. R., Lancet, 1964, 1, 1173.
} 